Article

\title{
The Economic Value of Mangroves: A Meta-Analysis
}

Marwa E. Salem ${ }^{1,2, *}$ and D. Evan Mercer $^{3}$

1 Department of Economics, North Carolina State University, 2801 Founders Drive, Raleigh, NC 27695, USA

2 Faculty of Economics and Political Science, Cairo University, Tharwat St., Giza, 12613, Egypt

3 Southern Research Station, USDA Forest Service, PO Box 12254, Research Triangle Park, NC 27709, USA; E-Mail: emercer@fs.fed.us

* Author to whom correspondence should be addressed; E-Mail: mesalem@ncsu.edu or marwassalem@yahoo.com; Tel.:+1-919-348-3460; +20-100-100-1020; Fax: +1-919-515-1824.

Received: 4 January 2012; in revised form: 25 February 2012 / Accepted: 28 February 2012 / Published: 7 March 2012

\begin{abstract}
This paper presents a synthesis of the mangrove ecosystem valuation literature through a meta-regression analysis. The main contribution of this study is that it is the first meta-analysis focusing solely on mangrove forests, whereas previous studies have included different types of wetlands. The number of studies included in the regression analysis is 44 for a total of 145 observations. We include several regressions with the objective of addressing outliers in the data as well as the possible correlations between observations of the same study. We also investigate possible interaction effects between type of service and GDP per capita. Our findings indicate that mangroves exhibit decreasing returns to scale, that GDP per capita has a positive effect on mangrove values and that using the replacement cost and contingent valuation methods produce higher estimates than do other methods. We also find that there are statistically significant interaction effects that influence the data. Finally, the results indicate that employing weighted regressions provide a better fit than others. However, in terms of forecast performance we find that all the estimated models performed similarly and were not able to conclude decisively that one outperforms the other.
\end{abstract}

Keywords: mangroves; meta-regression analysis; nonmarket valuation 


\section{Introduction}

Occurring at the intersection of land and sea within $30^{\circ}$ of the Equator, mangrove forests thrive in coastal zones characterized by desiccating heat, choking mud, and salt levels that would kill most plants [1]. Nevertheless, mangrove ecosystems are among the most productive and biologically complex ecosystems on the planet and provide us with a myriad of essential ecosystem services [2-5]. Mangroves provide pivotal support to commercial fisheries acting as nursery, breeding, spawning and hatching habitats for offshore fisheries [6-8] and exporting organic matter to the marine environment, producing nutrients for fauna in both the mangroves themselves and in adjacent marine and estuarine ecosystems [9]. Mangroves also play a crucial role in shoreline protection, where they serve as natural barriers, dissipating the destructive energy of waves and reducing the impact of hurricanes, cyclones, tsunamis and storm surges. Several studies have documented that regions with intact mangroves were exposed to significantly lower levels of devastation from cyclones than those with degraded or converted mangroves $[6,7,10,11]$. Mangroves play a significant role in stabilizing fine sediments, contributing to shore stabilization and erosion control [3,9]. Additionally, mangrove forests are often a rich source of timber, fuel wood, honey, medicinal plants and other raw materials [7,9]. Finally, they attract ecotourists, fishers, hunters, hikers and birdwatchers providing a valuable realized or potential source of national income.

Despite the vital ecosystem services they provide, mangroves are threatened worldwide. In many parts of the world they are rapidly being converted to salt evaporation ponds, aquaculture, housing developments, roads, ports, hotels, golf courses, and farms. In South and Southeast Asia, where 41.4\% of the world's mangroves occur [12], shrimp farms are being established on sites previously occupied by productive mangrove swamps [3]. Mangrove trees are also under exploitative pressure in areas, such as Indonesia, for their resources such as timber, fuel wood, and charcoal in addition to being cleared for agricultural purposes [13-15]. The mangroves that survive conversion are often threatened by oil spills, chemical pollution, sediment overload, and disruption of their sensitive water and salinity balance [1].

One reason mangrove forests are threatened is the public-good, non-market nature of many of the ecosystem goods and services they provide [16,17]. Due to the difficulty in estimating the value of the non-market ecosystem services, intact mangrove forests are often undervalued in benefit cost analyses of conservation versus other commercial land uses. Properly accounting for the multiple services provided by mangroves is necessary for making efficient choices between developing mangroves and management alternatives that entail more conservation and less conversion and exploitation of mangroves [14]. Developing accurate estimates for the value of intact mangrove forests is also needed for assessing damages from events such as oil spills. Oil spills, especially large-scale ones, have potentially devastating effects on mangroves, the flora and fauna sheltered by them, and the ecological services they provide [18]. Accordingly, mangroves are ranked among the most sensitive of shoreline regions in the Environmental Sensitivity Index (ESI) of the National Oceanic and Atmospheric Administration (NOAA), which measures how sensitive an area of shoreline would be to an oil spill [19].

The worldwide decline of mangrove forests has instigated a wide range of efforts to estimate the economic value of mangrove ecosystems [3,20-24]. Numerous studies have attempted to value 
mangrove ecosystems and their services in a wide range of geographic regions using a variety of valuation methods. Furthermore, there have been several meta-analyses conducted with regards to wetlands values in general [17,25-29]. However, to the authors' knowledge, there has been no attempt to undertake a mangrove-specific meta-regression analysis aimed at identifying underlying factors that affect annual per hectare mangrove values. Several studies have assembled data related to mangrove valuations conducted by other studies [16,30] without incorporating a regression component in the analysis while others have sought to identify a quantitative relationship between mangrove habitat area and shrimp production [31-33]. Therefore, the objective of this paper is to present a mangrove-specific meta-analysis examining the factors that determine mangrove economic valuations.

The rest of this paper is organized as follows. Section 2 reviews the different methods used to value the ecosystem services provided by mangroves. Section 3 provides an overview of the methodology used in the analysis. Data and summary statistics are presented in Section 4. Section 5 includes the estimation results and discussion followed by conclusions in section 6 .

\section{Mangrove Ecosystem Services and Valuation Methods}

As noted above, mangroves provide a wide range of vital ecosystem services, which have an equally wide range of value. Economists generally decompose the total economic value of ecosystems into direct use, indirect use and non-use values. Direct use values refer to consumptive and non-consumptive uses that entail direct physical interaction with the mangroves and their services [34] such as outputs of fish, fuel wood, recreation, and transport. Indirect use values include regulatory ecological functions [34], which lead to indirect benefits such as flood control, storm protection, nutrient retention, nursery grounds for different species, and erosion control. Nonuse values include existence and bequest values of mangroves [3]. Table 1 summarizes these services, as well as the methods most commonly used in their valuation.

Methods for valuing ecosystem services vary depending on the nature of the service. For ecosystem functions that produce marketable goods and services, prices are used in several alternative methods. The first is the production function approach (PF), which is based on the notion that the ecological function is an input to the production process and its value is measured by its effect on the productivity of marketed outputs [35]. PF measures the value as the change in consumer surplus (CS) and producer surplus (PS) that result from the change in the quantity or quality of the environmental good $[17,36]$. The net factor income approach (NFI) measures the value of the environmental service as the change in PS by subtracting the cost of other production inputs from total revenue of the marketable good. The market prices (MP) method assigns the total revenue derived from the marketable goods and services as the value of the ecosystem service that generated them. However, MP estimates are often upward biased since the cost of other production inputs are neglected [17]. 
Table 1. Ecological mangrove functions, economic goods and services, types of value, and commonly applied valuation methods.

\begin{tabular}{|c|c|c|c|}
\hline Ecological function & $\begin{array}{l}\text { Economic goods and } \\
\text { services }\end{array}$ & Value type & $\begin{array}{l}\text { Commonly used } \\
\text { valuation } \operatorname{method}(s) *\end{array}$ \\
\hline Flood and flow control & Flood protection & Indirect use & $\begin{array}{l}\mathrm{RCM} \\
\mathrm{MP}\end{array}$ \\
\hline $\begin{array}{l}\text { Storm buffering/ sediment } \\
\text { retention }\end{array}$ & Storm protection & Indirect use & $\begin{array}{c}\mathrm{RCM} \\
\mathrm{PF}\end{array}$ \\
\hline \multirow{2}{*}{$\begin{array}{l}\text { Water quality } \\
\text { maintenance/nutrient } \\
\text { retention }\end{array}$} & Improved water quality & Indirect use & CVM \\
\hline & Waste disposal & Direct use & $\mathrm{RCM}$ \\
\hline \multirow{4}{*}{$\begin{array}{l}\text { Habitat and nursery } \\
\text { for plant and animal } \\
\text { species }\end{array}$} & $\begin{array}{l}\text { Commercial fishing and } \\
\text { hunting }\end{array}$ & Direct use & $\begin{array}{l}\text { MP } \\
\text { NFI } \\
\end{array}$ \\
\hline & $\begin{array}{l}\text { Recreational fishing and } \\
\text { hunting }\end{array}$ & Direct use & $\begin{array}{l}\text { TCM } \\
\text { CVM }\end{array}$ \\
\hline & $\begin{array}{l}\text { Harvesting of natural } \\
\text { materials }\end{array}$ & Direct use & $\begin{array}{l}\text { MP } \\
\text { NFI }\end{array}$ \\
\hline & Energy resources & Direct use & $\begin{array}{l}\text { MP } \\
\text { NFI }\end{array}$ \\
\hline Biodiversity & $\begin{array}{l}\text { Appreciation of species } \\
\text { existence }\end{array}$ & Non-use & CVM \\
\hline Carbon sequestration & Reduced global warming & Indirect use & $\mathrm{RCM}$ \\
\hline \multirow{2}{*}{ Natural environment } & Recreation, tourism & Direct use & $\begin{array}{l}\text { CVM } \\
\text { TCM }\end{array}$ \\
\hline & $\begin{array}{l}\text { Existence, bequest, option } \\
\text { values }\end{array}$ & Non-use & CVM \\
\hline
\end{tabular}

Source: Adapted from Brander et al. [17] who adapt with modifications from Barbier [37,38], Brouwer et al. [39], and Woodward and Wui [27]. * Abbreviations represent: market prices (MP), production function method (PFM), travel cost method (TCM), contingent valuation method (CVM), replacement cost method (RCM), and net factor income (NFI).

Contingent valuation (CVM), currently the only method available to assess nonuse values, has been used for measuring both large discrete and marginal changes in ecosystem goods and services. CVM involves the use of surveys to elicit responses from people about their maximum willingness-to-pay (WTP) or willingness-to-accept (WTA) for hypothetical changes in environmental quality. The welfare measures estimated using the CVM are compensating and equivalent surplus [17,40,41]. Travel cost (TC) models are used to assess the recreational value of an ecosystem, such as evaluating the losses occurring from beach closures after oil spills [42]. The main idea behind the use of travel costs to assess the recreational demand of a site is that they act as implicit prices since an individual would have to incur these costs in order to complete the visit $[39,43]$. The use value of a recreational site is the sum of the total WTP of all individuals using that site [44]. TC measures the change in CS.

The replacement cost method (RCM) assumes that the value of the ecosystem service is equal to the cost of replacing it with a manmade alternative. Freeman [39] argues that three conditions must be met for the RCM to accurately estimate the value of the service. First, the manmade alternative must be the 
least costly method of replacement. Second, the service provided by the alternative must be of equivalent quality and magnitude. Third, individuals must be willing to incur this cost to replace the service if the natural resource is destroyed. Since replacement costs are not based on consumers' demand over ecosystem services, the RCM is not expected to provide accurate measure of CS and PS [17].

\section{Methods}

The goal of this paper is to use meta-analysis to assess the factors that potentially have a role in determining the annual per hectare value of mangrove forests. The most prominent advantage of meta-analysis is that it overcomes the problem of researcher subjectivity that characterizes literature reviews, whereby researchers often subjectively decide which studies to include and set aside others that they consider to be "weak". Instead, meta-analyses provide a statistical framework that incorporates evidence from the entire literature in a way that enables superior summarization and interpretation. Consequently, hundreds of meta-analysis applications have been carried out in the last few decades in the medical and social sciences $[45,46]$.

Meta-regression analysis (MRA) is particularly useful for the purpose of examining the findings of empirical studies in economics. MRA involves a dependent variable drawn from each study, in addition to independent variables that encompass the range of factors underlying differences among the studies such as method, design and data [45,46]. Following Woodward and Wui [27], Brander et al. [17], Ghermandi et al [29] and Chen [28], we estimate the base semi-logarithmic model of the following form in matrix notation:

$$
\ln (y)=c+X_{m} \beta_{m}+X_{v} \beta_{v}+X_{d} \beta_{d}+\mu
$$

where $c$ is the constant term, the dependent variable is the natural $\log$ of the annual per hectare mangrove values in 2010 US\$, the $\beta$ vectors represent the vectors of coefficients of the respective $X$ matrices and $\mu$ is the vector of residuals, assuming well-behaved error terms. The independent variables encompass study characteristics, $X_{v}$, mangrove characteristics, $X_{m}$, and $X_{d}$, GDP per capita. Variable definitions and summary statistics are displayed in Table 2.

Table 2. Variable definitions and summary statistics (in US\$ $\mathrm{ha}^{-1} \cdot \mathrm{yr}^{-1}$ ).

\begin{tabular}{|c|c|c|c|}
\hline Variable & Definition and units & $\begin{array}{c}\text { Mean } \\
\text { (St. dev.) }\end{array}$ & $N$ \\
\hline \multicolumn{4}{|c|}{ Study characteristics ${ }^{b}$} \\
\hline Average value & $\begin{array}{l}\text { Baseline category. }{ }^{\text {a }} \text { It depicts when the value is taken as an } \\
\text { average over the entire area of mangroves. }\end{array}$ & $0.74(0.44)$ & 108 \\
\hline Marginal value & 1 if the value was calculated per hectare and 0 otherwise & $0.260(0.44)$ & 38 \\
\hline Publication year & Year of publication & $2000(7.13)$ & 146 \\
\hline MP & Baseline category ${ }^{a}$ & $0.411(0.494)$ & 60 \\
\hline Static PF & 1 if a static production function was used and 0 otherwise & $0.014(0.117)$ & 2 \\
\hline Dynamic PF & 1 if a dynamic production function was used and 0 otherwise & $0.068(0.253)$ & 10 \\
\hline
\end{tabular}


Table 2. Cont.

\begin{tabular}{|c|c|c|c|}
\hline Variable & Definition and units & $\begin{array}{c}\text { Mean } \\
\text { (St. dev.) }\end{array}$ & $N$ \\
\hline \multicolumn{4}{|c|}{ Mangrove characteristics $^{c}$} \\
\hline Other regressions & 1 if other regressions were used and 0 otherwise & $0.034(0.182)$ & 4 \\
\hline NFI & 1 if the net factor income method was used and 0 otherwise & $0.192(0.395)$ & 28 \\
\hline $\mathrm{RC}$ & 1 if the replacement cost method was used and 0 otherwise & $0.212(0.410)$ & 31 \\
\hline $\mathrm{CV}$ & $\begin{array}{l}1 \text { if the contingent valuation method was used } \\
\text { and } 0 \text { otherwise }\end{array}$ & $0.068(0.253)$ & 10 \\
\hline \multicolumn{4}{|c|}{ Mangrove characteristics $^{\mathrm{c}}$} \\
\hline Area & Area of the mangrove site in logarithm form & $8.65(2.937)$ & 146 \\
\hline Local & Baseline category & & \\
\hline Global & $\begin{array}{l}1 \text { if exports or the contribution of foreign visitors represents } \\
\text { a significant portion of value and zero otherwise }\end{array}$ & & \\
\hline Thailand & Baseline category $^{\text {a }}$ & $0.219(0.415)$ & 32 \\
\hline Asia (excl. Thailand) & 1 if in Asia but not Thailand and 0 otherwise & $0.514(0.502)$ & 75 \\
\hline Middle East \& Africa & 1 if in the Middle East and Africa and 0 otherwise & $0.075(0.265)$ & 11 \\
\hline Americas & 1 if in the Americas and 0 otherwise & $0.123(0.33)$ & 18 \\
\hline Other continent & 1 if in Fiji or Micronesia and 0 otherwise & $0.068(0.253)$ & 10 \\
\hline Protected & $\begin{array}{l}1 \text { if site is designated as RAMSAR or provided any other } \\
\text { legal protection by the state and } 0 \text { otherwise }\end{array}$ & $0.486(0.502)$ & 71 \\
\hline Fisheries & Baseline category ${ }^{\text {a }}$ & $0.349(0.478)$ & 51 \\
\hline Forestry & 1 if a forestry product and 0 otherwise & $0.24(0.43)$ & 35 \\
\hline Recreation & 1 if tourism, recreation, or research and 0 otherwise & $0.096(0.295)$ & 14 \\
\hline Coastal protection & $\begin{array}{l}1 \text { if coastal protection and stabilization or flood control } \\
\text { and } 0 \text { otherwise }\end{array}$ & $0.197(0.40)$ & 29 \\
\hline Carbon sequestration & 1 if carbon sequestration and 0 otherwise & $0.048(0.214)$ & 7 \\
\hline Nonuse & 1 if a nonuse value and 0 otherwise & $0.041(0.199)$ & 6 \\
\hline Water \& air quality & $\begin{array}{l}1 \text { if water and air purification or waste assimilation } \\
\text { and } 0 \text { otherwise }\end{array}$ & $0.027(0.164)$ & 4 \\
\hline GDP per capita & GDP per capita in logarithmic form & $6.71(2.345)$ & 146 \\
\hline
\end{tabular}

\footnotetext{
${ }^{a}$ Baseline category refers to that which is excluded for each categorical variable in order to avoid perfect collinearity. ${ }^{b}$ The category of the TCM was removed since it was represented by only one observation. ${ }^{c}$ The observations representing biodiversity, nutrient retention and traditional uses were excluded since each only had one observation.
}

Several points should be noted concerning the variables used in the model. The log form for area and GDP per capita produced better fitting models. The use of the continent dummy variables should capture location effects on mangrove values. The choice of Thailand to be the baseline category was based on the distribution of observations among the continents. Asia accounts for about $73 \%$ of the observations, while the rest of the continents are somewhat similar in the number of observations making them unlikely candidates for being the excluded category, since each accounts for only a small percentage of the overall dataset. In Asia, Thailand accounts for nearly a third of the observations, making it the largest contributor to our dataset. Alternatively, breaking Asia into the country level would generate more variables than would be appropriate given the total number of observations. 
Consequently, we ran an $F$-test between the two models excluding Asia as a whole in one and excluding only Thailand in the other. We were not able to reject the null that the two models are not significantly different. Unlike other studies pertaining to wetlands in general, we have not included the latitude and longitude coordinates of the location of each site because unlike wetlands, which are geographically dispersed, mangroves predominantly occur in tropical regions and hence do not exhibit as much geographic variability [47]. The publication year is included to capture developments or innovations in valuation techniques, which may affect estimates. The GDP per capita represents the socio-economic condition of the different countries the mangrove forests are located in.

A noteworthy point on the variables involves the accounting framework of the ecosystem goods and services valuation. Fisheries production is calculated either as a percentage of the total catch of the fish landings that can be attributed to mangroves, or by using a production function of some kind. The value of the fish, as well as that of forestry products, is computed by using market or surrogate prices. Costs of production may then be deducted or not, depending on the available data, resulting in either the MP or NFI approach being used. The value of coastal protection and stabilization is calculated either as the replacement cost of constructing man-made alternatives that would provide the service, the value of the property that may be damaged without the service, or the value attached by the community to the service. Tourism and recreation are computed as the revenues that accrue to the community by visitors, either local or foreign. Carbon sequestration is calculated as the product of the carbon sequestration rates in the site being valued and a global price of carbon, taken from a source such as the World Bank reports. Nonuse values are always assessed through surveys aimed at soliciting individuals' willingness-to-pay (WTP) for the existence, bequest, or option values of mangroves. A factor that may impact the magnitude of valuation is whether a significant part of the good or service is exported to a foreign market or whether the contribution of foreigners to values such as tourism is large.. The categorical variable Global captures this factor.

The joint production of ecosystem services as well as the ecological health of the mangroves may also impact mangrove valuations. It is widely recognized that there are intricate relationships and tradeoffs between ecosystem services [48-50]. For example, the over-harvesting of mangroves for timber leads to high, unsustainable rates of deforestation that in turn, negatively impact the productivity of other services such as providing nursery and breeding grounds for fisheries. Even though the mangroves are generally harvested or cleared in all the studies we have covered, we have not found studies that explicitly value this tradeoff between different goods and service in mangroves. Some studies such as Ruitenbeek [14], Ong and Padilla [51] and Gammage [52] examine alternative management strategies that involve focussing on one service or tanother. For each strategy, they compute the potential value of the fisheries and/ or forestry values given certain assumptions,. However, in this analysis, we have included only the values that represent the status quo and not potential values.

Even though the health of mangroves is expected to greatly impact their productivity, the ecological status is not always evident in the primary studies. To our knowledge there have been no attempts to monetarily quantify the loss in ecosystem services associated with deterioration in mangrove function performance. Possible exceptions could be Sanchirico and Mumby [53] and Sanchirico and Springborn [54], who used the percent of mangrove cover as an indicator of mangrove availability. Insofar as a reduced cover percent could be construed as compromised health, these papers can be 
considered as incorporating mangrove health in determining ecosystem service values. However, the two papers did not offer quantitative values per unit area of mangrove forest.

We estimate three separate regression models. In model 1, we use ordinary least squares (OLS) with robust standard errors [55]. In model 2, we deal with the issue of the potential presence of outliers in the data by running a robust regression [56,57]. Finally, in model 3, we address the issue of the likely correlation between observations of the same study (the majority of the studies used in the analysis provide more than one estimate). We employ a method commonly used in the literature [29,58,59], giving each study the same weight by assigning each observation a weight equal to the inverse of the number of observations included in that study [60]. Since a comparison of models 1 and 2 reveal that the outliers present in the data have an effect on the results, the weighted regression is also estimated with the robust procedure used in model 2. In section 5 , we report the results of model 3 since it generally provided the best fit. We report the results for models 1 and 2 in the supplementary material.

\section{Data}

We compiled a total of 73 studies encompassing 352 observations of mangrove ecosystem service valuations of either monetary or physical quantities (e.g., cubic meters of timber or tons of fish). The list of studies is provided in the supplementary material. The studies included journal articles, project reports, book chapters and 'grey literature'. Care was taken to avoid double counting valuations that were benefit transfers from other studies in our database. For estimates reported by the same author(s) in different studies, the oldest study was used, when possible. Every effort was made to obtain the primary studies where mangrove valuations are reported. However, whenever that was not possible, the valuations were taken from the citing study, and both the original and citing studies were referenced [61].

The data is described in two ways: quantities and values, both of which are expressed per hectare per year $\left(\mathrm{ha}^{-1} \cdot \mathrm{yr}^{-1}\right)$. In the former, we describe the ranges of mangrove productivity of goods for which physical quantities were specified in the primary studies. The number of observations of physical quantities was 114 and their summary statistics are presented in Table 3. In the latter, only the values that are used in the regression analysis are included and are summarized by service and by valuation method.

Selecting and standardizing the values for the regression analysis entailed several steps. First, studies that reported only physical quantities but not monetary valuations were dropped, as were all observations with missing values. Some observations were reported on a per household basis, not per unit area and hence were also excluded from the analysis. Additionally, due to the inconsistencies between studies, we aggregated detailed estimates to make studies more comparable. For example, some studies report valuations for aggregate fisheries, while others break them down into fish, shellfish and shrimp, or fish and invertebrates. To overcome this, we aggregated all fishery-related goods into "aggregate fisheries". Reports of total economic valuations for the whole mangrove ecosystem were not used since they include different environmental services, which in turn entail different valuation methods. Accordingly, these estimates are not conductive to assessing the factors that affect annual per hectare mangrove value. 
For standardizing valuations, we follow Woodward and Wui [27] and Brander et al. [17] in using country GDP deflators and PPP conversion factors taken from the World Development Indicators toconvert all values to US dollars. Another issue was that some studies reported marginal values while others reported total or average values. Costanza et al. [62] assert that average productivity is more appropriate for the evaluation of large areas, while marginal values should be used in assessing small area values. We followed Brander et al. [17] and assumed that marginal and average values are equal, i.e., that mangrove values exhibit constant returns to scale. We later include area as an explanatory variable in order to examine the returns to scale of mangrove area.

The final number of studies included in the analysis was 44 for a total number of 149 observations. The observations span 18 countries in Asia, the Americas, the Middle East and Africa. We created the variable 'other continent' to represent Fiji and Micronesia. The methods of valuation employed in our dataset include market prices, replacement cost (including costs avoided and maintenance costs avoided), net factor income, travel cost, and both static and dynamic versions of the production function approach. Several other production function models have been used, namely, the Schaefer-Gordon model, the Leontief production function, the Pauly and Ingles production function as well as a scaling model [63]. In the following analysis, we group the latter four production function models, into one variable, "other regressions".

To allow more consistency with the definitions used in the valuation studies, we categorize the ecosystem services included in the dataset differently than in previous wetland meta-analyses, The services are: (1) fisheries, which depict the value of fish and shellfish supported by mangrove forests, including support as nursery and breeding grounds, (2) forestry, which includes timber, fuel wood, charcoal, and other forestry products, (3) recreation, which includes tourism and research expenditures, (4) storm protection and coastal protection and stabilization, (5) carbon sequestration, (6) nonuse values, including option, bequest and existence values, (7) water and air purification as well as waste assimilation, (8) nutrient retention, (9) biodiversity and (10) traditional uses from hunting, fishing and gathering. The last category includes a value that incorporated elements of both forestry and fisheries without segregating them into separate values and so was listed as a separate category.

Table 3. Quantities of goods provided by mangrove forests $\left(\mathrm{ha}^{-1} \cdot \mathrm{yr}^{-1}\right)$.

\begin{tabular}{lcccccc}
\hline \multicolumn{1}{c}{ Variable } & Obs. & Mean & Std. Dev. & Min & Max & Median \\
\hline Fish, shellfish, molluscs $(\mathrm{Kg}) *$ & 29 & 539 & 748 & 10 & 2,500 & 126 \\
Shrimp $(\mathrm{Kg})$ & 22 & 146 & 119 & 6 & 349 & 109 \\
Timber $(\mathrm{Kg})$ & 3 & 5,976 & 6,658 & 289 & 13,300 & 4,340 \\
Timber $\left(\mathrm{m}^{3}\right)$ & 13 & 6 & 4 & 1 & 13 & 5 \\
Fuel wood, charcoal $(\mathrm{Kg})$ & 6 & 5,140 & 11,393 & 6 & 28,370 & 511 \\
Fuel wood, charcoal $\left(\mathrm{m}^{3}\right)$ & 7 & 102 & 102 & 2 & 230 & 92 \\
Carbon $(\mathrm{Mg}) * *$ & 34 & 5.27 & 15.41 & 0.02 & 90.5 & 1.69 \\
\hline * Two observations also include shrimp. & $* * \mathrm{Mg}=$ metric ton $=10^{6} \mathrm{~g}$. & &
\end{tabular}

Table 3 shows that all goods are quantified in $\mathrm{Kg}$., while timber, fuel wood and charcoal are further quantified in some studies in terms of $\mathrm{m}^{3}$. In describing the productivities, we aggregated fish and shellfish together, but left shrimp separate since studies often focus on shrimp because of its higher value. It is not feasible to compare productivities across services because of their heterogeneity. 
Fisheries, either on-shore or off-shore, that depend on mangroves produce an average of $539 \mathrm{Kg} \cdot \mathrm{ha}^{-1} \cdot \mathrm{yr}^{-1}$ of fish and shellfish and $146 \mathrm{Kg} \cdot \mathrm{ha}^{-1} \cdot \mathrm{yr}^{-1}$ of shrimp. These averages lie within the value ranges found by other studies [16,64]. Mangrove forests produce on average $5976 \mathrm{Kg} \mathrm{ha}{ }^{-1} \cdot \mathrm{yr}^{-1}$ of timber and $5140 \mathrm{Kg} \mathrm{ha}{ }^{-1} \cdot \mathrm{yr}^{-1}$ of fuel wood and charcoal. The forests further sequester an annual mean of $5.27 \mathrm{Mg}$ of carbon $\mathrm{ha}^{-1} \cdot \mathrm{yr}^{-1}$. All medians are lower than the means, indicating skewed value distributions. However, some services are much more heavily skewed with long right tails, such fish and shellfish, carbon, and timber $(\mathrm{Kg})$.

Figure 1 shows the distribution of observations by location. The observations are significantly concentrated in Asia [65]. The reason for this may be partly because mangroves in South and Southeast Asia account for $41.4 \%$ of the world's mangroves [12]. Another reason may lie in the motivations behind many of the studies, which were to carry out a cost-benefit analysis of converting mangroves to alternative uses, such as shrimp aquaculture or to quantify the cost of overexploiting mangroves for extractive purposes. We expect that these uses of mangroves are relatively more prevalent in Southeast Asia than they are in North America or Africa and the Middle East. Evidence of this may be found in Brander et al. [17], who employ 80 wetland studies comprising 215 observations, over half of which are concentrated in North America. When examining the distribution of observations in their study according to type of wetland service, we find that the number of amenity and recreation observations account for a significantly larger proportion of total observations than in our study (see Table 4). Accordingly, we may infer that the study location affects the type of ecosystem service being evaluated [66].

Figure 1. Distribution of observations by continent.

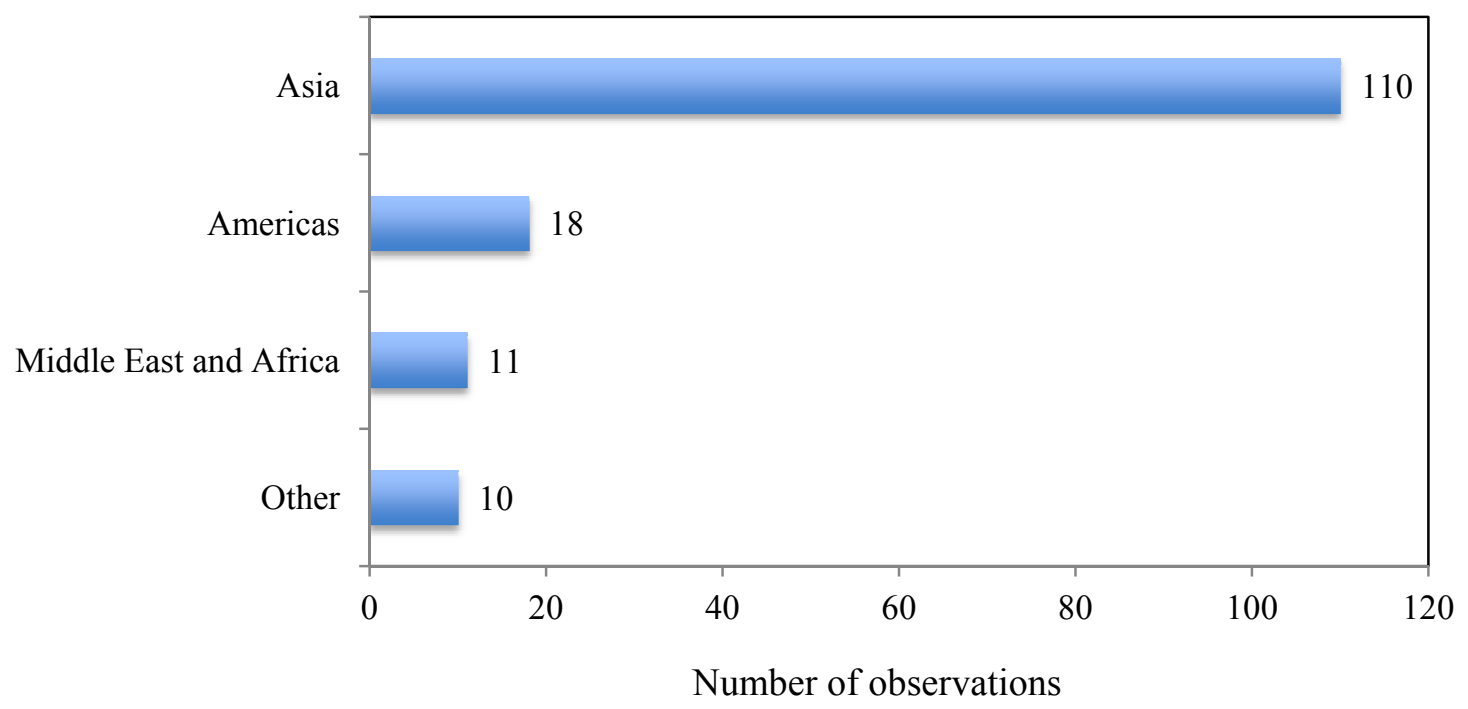

Table 4 presents summary statistics for valuations by type of service. The observations representing total economic values, and which have been excluded from the analysis, lie in the range of $\$ 2,772$ to $\$ 80,334 \mathrm{US} \$ \mathrm{ha}^{-1} \cdot \mathrm{yr}^{-1}$ with a mean of $\$ 28,662 \mathrm{US} \$ \mathrm{ha}^{-1} \cdot \mathrm{yr}^{-1}$ and a median of $\$ 3,847 \mathrm{US} \$ \mathrm{ha}^{-1} \cdot \mathrm{yr}^{-1}$. This indicates a heavily left-skewed distribution, a characteristic that is also found among per hectare values distributed according to type of service and method of valuation (see Tables 4 and 5, respectively). As is evident in Table 4 , the highest average service value is forestry $(\$ 38,115)$ followed 
closely by recreation and tourism $(\$ 37,927)$, while the lowest is nutrient retention $(\$ 44)$. However, due to the highly skewed nature of the data, the medians portray a different picture. Nonuse values have the highest median by a large margin $(\$ 15,212)$, followed by purification and waste assimilation services $(\$ 5,801)$ and coastal protection $(\$ 3,604)$. Hence, indirect use and nonuse values have higher medians than direct use values.

Table 4. Summary statistics for mangrove valuations by type of service (in US\$ $\mathrm{ha}^{-1} \cdot \mathrm{yr}^{-1}$ ).

\begin{tabular}{lrrrrr}
\hline \multicolumn{1}{c}{ Service } & Obs. & Mean & Min & \multicolumn{1}{c}{ Max } & Median \\
\hline Fisheries & 51 & 23,613 & 10.05 & 555,168 & 627 \\
Forestry & 35 & 38,115 & 18.00 & $1,287,701$ & 576 \\
Coastal protection & 29 & 3,116 & 10.45 & 8,044 & 3,604 \\
Recreation \& tourism & 14 & 37,927 & 1.74 & 507,368 & 1,079 \\
Nutrient retention & 1 & 44 & - & - & - \\
Carbon sequestration & 7 & 967 & 39.89 & 4,265 & 211 \\
Nonuse & 6 & 17,373 & 3.77 & 50,737 & 15,212 \\
Biodiversity & 1 & 52 & - & - & - \\
Water and air purification/ waste & 4 & 4,748 & 12.43 & 7,379 & 5,801 \\
assimilation & 1 & 114 & - & - & - \\
Traditional uses & 149 & & & & \\
Total & & & & & \\
\hline
\end{tabular}

Values are significantly more diversified when categorized according to method of valuation, as can be seen in Table 5. The highest average value is given by production functions other than static and dynamic $(\$ 257,905)$, followed by MP $(\$ 31,990)$ and CVM $(\$ 10,691)$ while the lowest values are provided by the dynamic PF (\$209).

Table 5. Summary statistics for valuation observations by method of valuation (in US\$ $\left.\mathrm{ha}^{-1} \cdot \mathrm{yr}^{-1}\right)$.

\begin{tabular}{lrrrrr}
\hline \multicolumn{1}{c}{ Method } & Obs. & Mean & \multicolumn{1}{c}{ Min } & \multicolumn{1}{c}{ Max } & Median \\
\hline Static PF & 2 & 2,975 & 120 & 5,830 & 2,975 \\
Dynamic PF & 10 & 209 & 10 & 1,334 & 53 \\
Other regressions & 4 & 257,905 & 4,377 & 555,168 & 236,037 \\
Market prices & 62 & 31,990 & 2 & $1,287,701$ & 768 \\
Net factor income & 28 & 1,545 & 18 & 11,341 & 342 \\
Replacement cost & 32 & 3,390 & 12 & 8,044 & 3,889 \\
Contingent valuation & 10 & 10,691 & 4 & 50,737 & 1,082 \\
Travel cost & 1 & 8,094 & & & \\
Total & 149 & & & & \\
\hline
\end{tabular}

Figure 2 and Figure 3 present the valuations based on services and valuation methods, respectively. The boxes represent values from the 25th to the 75 th percentiles, and the line markers in the bars depict medians. The error bars identify the adjacent values, which are the most extreme values within 1.5 interquartile range ( $i q r)$ of the nearer quartile ( $i q r=75$ th quartile -25 th quartile). The $y$-axis is on a log scale and outliers that lie outside the error bars have been excluded. In Figure 2, the number of 
excluded observations for the services was: fisheries (3), forestry (4), tourism and recreation (1), and carbon sequestration (1). In Figure 3, the excluded observations are: dynamic PF (2), MP (6), and NFI (4). In Figure 2, three services with only one observation have been excluded. They are: biodiversity, nutrient retention and traditional uses of hunting, fishing and gathering. As Figure 2 shows, there is moderate overlap between values of different services. As was shown in Table 4, nonuse values have the highest median and are also the most widely dispersed. Purification and waste assimilation services follow in terms of values while the rest of the services lie in a somewhat similar range.

Figure 2. Distribution of mangrove valuations by type of service (in US $\$ \mathrm{ha}^{-1} \cdot \mathrm{yr}^{-1}$ ).

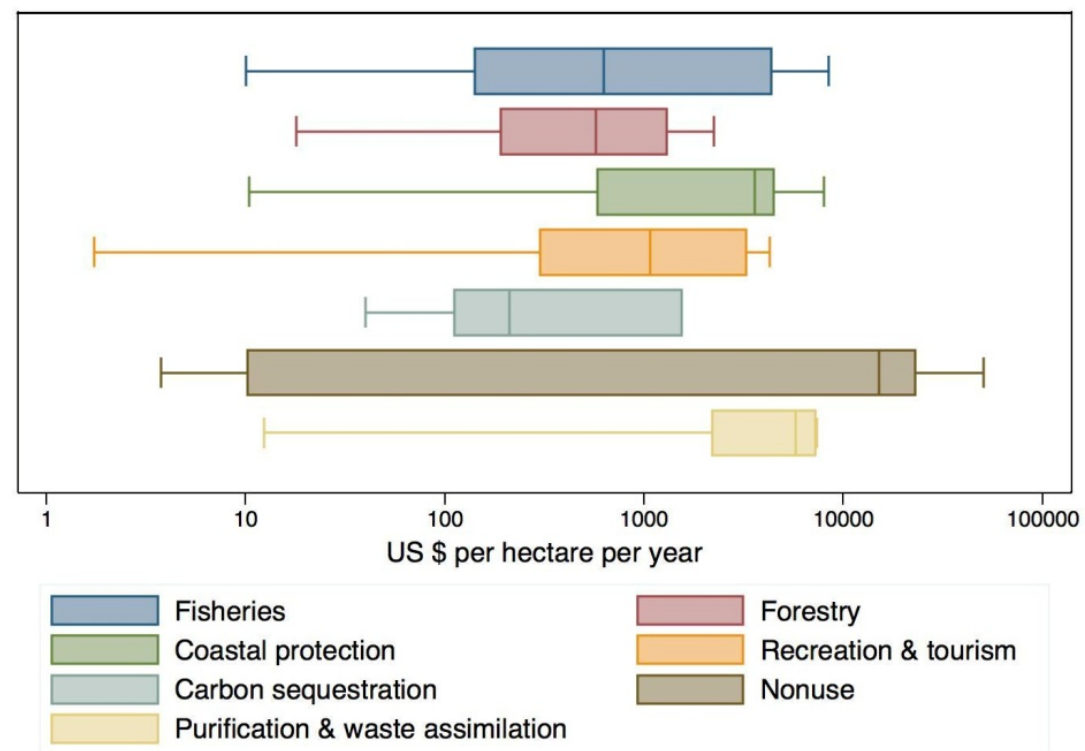

Figure 3. Distribution of mangrove valuations by method of valuation (in US $\$ \mathrm{ha}^{-1} \cdot \mathrm{yr}^{-1}$ ).

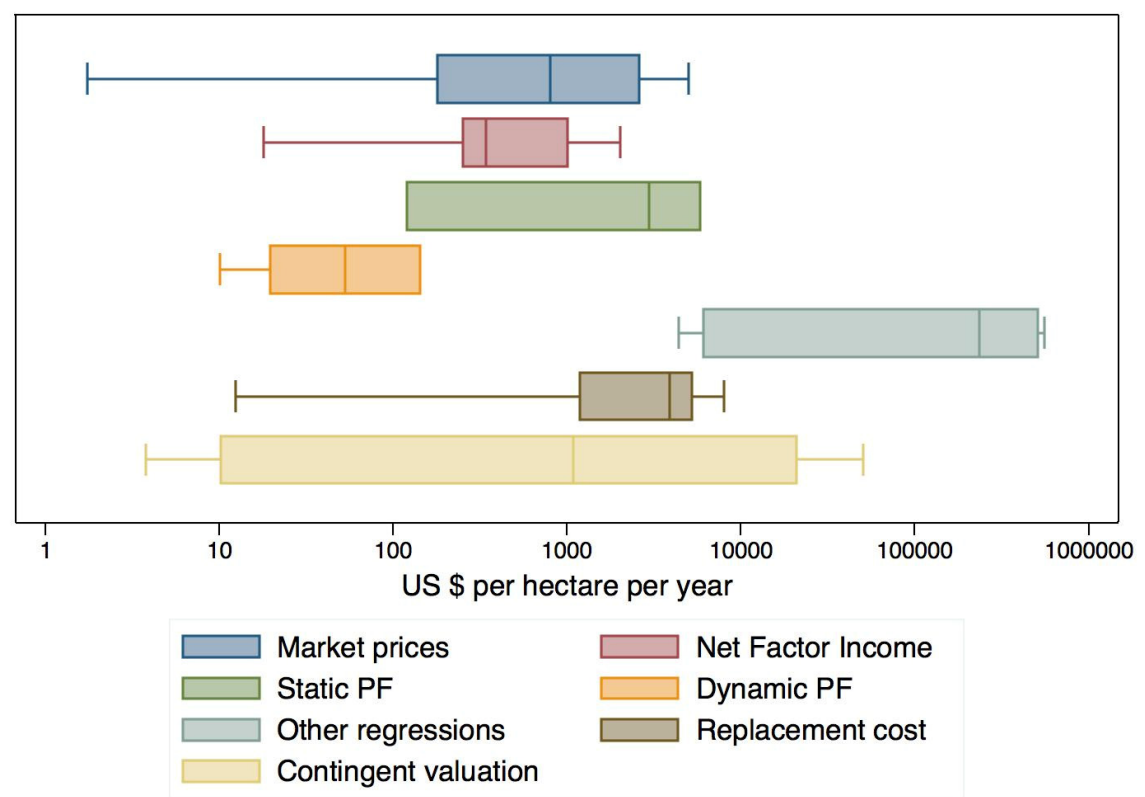


In Figure 3, the distribution of values confirms the information conveyed in Table 4. It is evident that "other regressions" provide the highest values, while the dynamic PF method gives the lowest median. However, not all valuation methods are used for all services, which is bound to influence the way values are distributed across valuation methods. For example, CVM is the only method that measures nonuse values, while MP and NFI are used when valuing forestry products. In Figure 4, we plot the distribution of values according to services and valuation method. We chose only those services for which more than one method was used in valuation, and for which each method has at least two observations. In this way, comparability between valuation methods becomes more feasible.

The methods used in valuing fisheries are MP, NFI and all types of production functions. Two methods were used to value coastal protection and stabilization, namely RC and CVM, while both the MP and RC methods were employed to measure the value of carbon sequestration. Comparing the first five boxes shows that MP values are slightly higher than those of NFI but do not differ significantly from static PF methods, though the latter are more dispersed. The dynamic PF gives lower values than other methods, while other regressions provide higher estimates. Values reported for coastal protection and stabilization are higher when the RC method is used than CVM. Similarly, the RC method generates higher values compared with MP in carbon sequestration valuations.

Figure 4. Distribution of mangrove valuations by service and method of valuation (in US\$ $\mathrm{ha}^{-1} \cdot \mathrm{yr}^{-1}$ ).

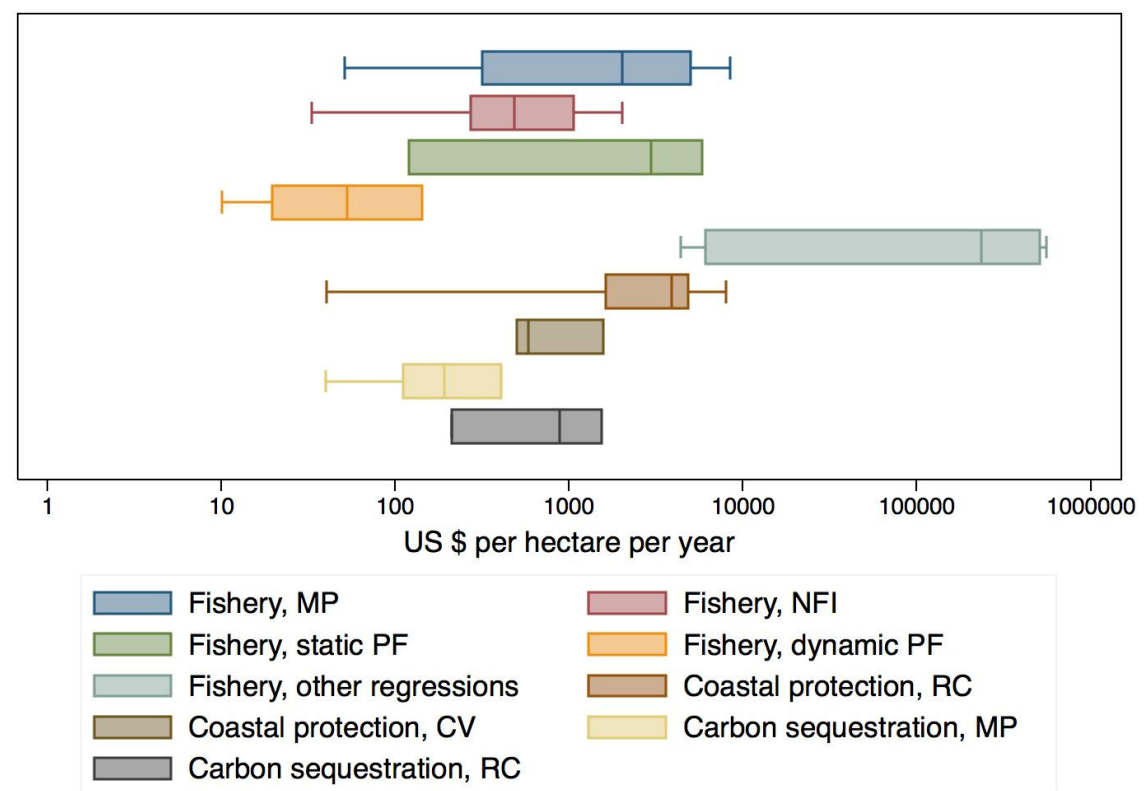

\section{Results and Discussion}

The total number of observations estimated in the model is 145 . Results of the weighted robust regression are displayed in Table 6 and labeled as model 1. The coefficients of the area and GDP per capita, being in logarithmic form, should be interpreted as elasticities. The coefficients of the categorical variables, on the other hand, show the effects of their respective variables on the dependent variable $[67,68]$. The variable representing publication year is removed due to multicollinearity 
problems. Additionally, we examine potential interaction effects of per capita GDP with type of ecosystem service. We included interaction terms to the model depicting the cross effects of the different services with GDP per capita (the interaction term of fisheries was excluded due to multicollinearity problems). The results are displayed in Table 6 as model 2. The number of observations flagged as gross outliers in models 1 and 2 were 2 and 3 observations, respectively.

Table 6. Estimation results ${ }^{\mathrm{a}}$.

\begin{tabular}{|c|c|c|}
\hline Variable & Model 1 & Model 2 \\
\hline Marginal value & $-1.066 * *(0.491)$ & $-1.274 * * *(0.4)$ \\
\hline Static PF & $-0.437(1.019)$ & $-0.328(0.802)$ \\
\hline Dynamic PF & $1.148 *(0.682)$ & $1.344 * *(0.544)$ \\
\hline Other regressions & $3.705 * * *(0.871)$ & $2.880 * * *(0.704)$ \\
\hline NFI & $-0.618 *(0.327)$ & $-0.614 * *(0.264)$ \\
\hline $\mathrm{RC}$ & $-0.791(0.881)$ & $3.103 * * *(0.819)$ \\
\hline $\mathrm{CV}$ & $-2.421(1.944)$ & $4.199 * * *(1.532)$ \\
\hline Log (area) & $-0.0774(0.056)$ & $-0.018(0.0463)$ \\
\hline Global & $0.674 *(0.377)$ & $-0.278(0.311)$ \\
\hline Asia (excl. Thailand) & $-0.833 *(0.427)$ & $-0.0462(0.355)$ \\
\hline Middle East \& Africa & $1.043(1.008)$ & $2.175 * * *(0.804)$ \\
\hline Americas & $-0.581(0.635)$ & $0.197(0.533)$ \\
\hline Other continent & $0.977(0.896)$ & $0.941(0.73)$ \\
\hline Protected & $0.845 * *(0.37)$ & $0.520 *(0.304)$ \\
\hline Forestry & $-0.455(0.342)$ & $0.294(0.412)$ \\
\hline Recreation & $-0.263(0.766)$ & $-0.00449(0.732)$ \\
\hline Coastal protection & $2.059 * *(0.949)$ & $-5.492 * * *(1.062)$ \\
\hline Carbon sequestration & $1.342 * *(0.543)$ & $-3.123 * * *(1.064)$ \\
\hline Nonuse & $5.809 * *(2.266)$ & $6.403 * *(2.533)$ \\
\hline Water \& air quality & $3.027 * *(1.502)$ & $7.869(11.19)$ \\
\hline $\log (\mathrm{GDP})$ & $0.866 * * *(0.0794)$ & $0.792 * * *(0.0664)$ \\
\hline Forestry_GDP per capita & & $-9.72 \times 10^{-5} * *\left(4.06 \times 10^{-5}\right)$ \\
\hline Recreation_GDP per capita & & $-2.07 \times 10^{-5}\left(2.79 \times 10^{-5}\right)$ \\
\hline Coastal protection_GDP per capita & & $0.000563 * * *(0.00013)$ \\
\hline Carbon sequestration_GDP per capita & & $0.000288 * * *\left(8.37 \times 10^{-5}\right)$ \\
\hline Nonuse_GDP per capita & & $-0.00119 * * *(0.00023)$ \\
\hline Water \& air quality_GDP per capita & & $-0.00204(0.003)$ \\
\hline Constant & $-0.0787(0.101)$ & $-0.0881(0.081)$ \\
\hline No. of observations & 143 & 142 \\
\hline Adjusted $R^{2}$ & 0.6 & 0.7 \\
\hline$F$ & $45.85 * * *$ & $59.45 * * *$ \\
\hline
\end{tabular}

${ }^{a}$ Robust standard errors are between parenthesis and the asterisks $* * *, * * *$ depict significance at the $10 \%, 5 \%$ and $1 \%$ levels, respectively.

First, we examine the effect of the study characteristics on mangrove valuation and find that both models provide consistent results with regards to statistically significant coefficients. Compared to the method of MP, $t$ dynamic and "other" $\mathrm{PF}$, as well as the RC and CVM methods provide higher estimates, while the NFI method generates lower estimates. However, the estimated coefficients of the 
static and dynamic PF methods should be interpreted with caution since only two studies used each method. This confirms our initial expectations regarding valuation magnitudes as shown in Figure 5, with the exception that the CVM produces higher estimates than the RCM and the rest of the methods. Similarly, Brander et al. [17] find that the CVM provides the highest estimates, while Woodward and Wui [27] find that the RC method produces higher values than CVM. Finally, marginal values are lower than average values, suggesting decreasing returns to scale. This is consistent with expectations in the literature about the relationship between marginal and average values [62]. Even though Brander et al. [17] find that marginal values are higher, they do conclude that values exhibit decreasing returns to scale based on area.

As for mangrove characteristics, we find that although the coefficients of area are negative, they are insignificant. Model 1 shows a positive, significant 'Global' coefficient, indicating that having the product exported or having foreign tourists account for a significant portion of value raises the value more than average. This effect disappears when the interaction terms are included, indicating that the Global variable was capturing this interactive income effect. The location variables show that only the coefficient of the Middle East and Africa is significant and positive, indicating higher values than average, consistent with the findings of Brander et al. [17]. This result is likely influenced by the particularly high values reported for Egypt, where the area of mangroves is among the smallest in the dataset, which are therefore highly valued.

Furthermore, we find the variable depicting protection to be positive and significant. In contrast, Brander et al. [17] find a negative relation between values and being designated as a RAMSAR site. However, a positive effect of protection on mangrove values is expected since protection entails higher productivity, especially with regards to ecological functions such as storm protection and acting as nursery grounds for fish and shellfish.

Considering the effect of the type of ecosystem service on values, the value of fisheries is included in the intercept. The ecological services of water and air quality as well as nonuse values are found to be higher than the value of fisheries, while forestry products and recreation are not significantly different. However, the models provide significant, but opposing results with regards to coastal protection and carbon sequestration. Model 1 provides positive estimates while model 2 produces negative estimates. This can be esplained by the interaction terms in model 2, which show positive and statistically significant estimates for both these services. This indicates that the positive estimates in model 1 may have been capturing this income effect. Brander et al. [17] and Ghermandi et al. [29] find that materials and recreation give lower than average values. Chen [28] and Ghermandi et al. [29] also find that water quality has higher than average values. The coefficient of GDP per capita is positive and statistically significant in both models, conforming to the findings of Brander et al. [17], Ghermandi et al. [29] and Chen [28].

The inclusion of cross effects reveal that service type affects mangrove values not just through the service itself, but also through its interaction with GDP per capita. The estimated coefficients are mostly found to be statistically significant. One might expect that ecological functions would be more valuable in countries with higher GDP per capita and that materials such as fuel wood and charcoal would be more valued in countries with lower GDP per capita, where such services are often used for subsistence purposes in villages. The significant coefficients of interaction terms mostly confirm this since the coefficient of forestry is negative, while those of carbon sequestration and coastal protection 
are positive. However, the unexpected result was that of nonuse interacted with GDP per capita, which is negative. We attribute this to the high value reported for Egypt, for which GDP per capita is below the average of countries in our dataset, and for which nonuse value is the highest in the dataset. The values reported for Egypt, while high, were not recognized as outliers by the procedure through which outliers were dropped as described in endnote [57].

Both models fit the data well as evidenced by the high adjusted $R^{2}$. However, the inclusion of the interaction terms has raised the explanatory power of the model.

Since one objective of meta-regression analysis is to provide a value transfer function for benefit transfer exercises, we examine two measures of forecast performance [17]. The first is an in-sample forecast performance measure, namely, the Mean Absolute Percentage Error (MAPE), defined as the mean of $\left|\left(y_{\text {obs }}-y_{\text {est }}\right) / y_{\text {obs }}\right|$. Additionally, as an out-of-sample forecast performance measure, we use a data-splitting technique whereby $n^{-1}$ transfer functions are estimated by iteratively omitting one observation, estimating the model and then applying the resulting estimated parameters to this observation. Comparing the predicted and observed values reveals how well the model performs against the data. The results of both measures are displayed in Table 7 .

Table 7. The in-sample and out-of-sample Mean Absolute Percentage Error (MAPE) of the estimated models.

\begin{tabular}{ccc}
\hline Performance Measure & Model 1 & Model 2 \\
\hline In-sample MAPE & 0.402 & 0.35 \\
Transfer MAPE & 0.488 & 0.54 \\
\hline
\end{tabular}

Figure 5. Out-of-sample transfer MAPE while observations are sorted in an ascending order based on annual per hectare mangrove values.

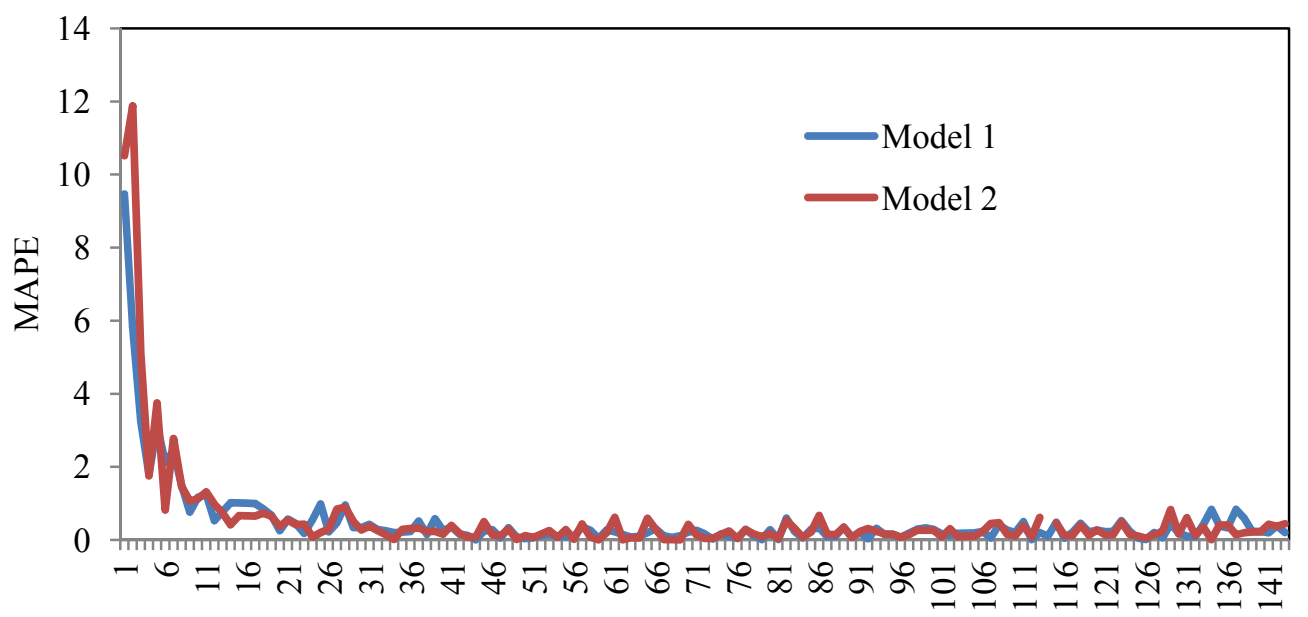

Observations

The in-sample MAPE shows that model 2 performs relatively better. Brander et al. [17] report a value of 58\% and Chen [28] reports values that range from about $13 \%$ to $44 \%$, indicating that our models perform relatively well. The out-of-sample forecast analysis, however, shows that model 1 performs slightly better. The corresponding values in Brander et al. [17] and Chen [28] are 74\% and $42 \%$ to $75 \%$, respectively, again indicating that the models presented here perform relatively well. 
Furthermore, the transfer errors lie well within the bounds reported by Brouwer [37], who reviewed several studies that have attempted value function transfer.

Figure 5 shows the plot of the values of the out-of-sample MAPE while sorting observations in an ascending order based on annual per hectare mangrove values. There are no significant differences between forecast performance among the two models. Both models perform considerably worse in predicting very low mangrove values than higher ones.

\subsection{Robustness Checks}

As previously mentioned, we estimated an OLS regression with robust standard errors as well as an unweighted robust regression model, the results of which are reported in the supplementary material. There are a few differences among the models. The dynamic PF approach is negative and statistically significant in these models. We attribute this difference to the high concentration of the dynamic PF method observations in one study [69], which reports relatively low values. When these observations are given less weight, their effect is reduced and becomes positive. Another difference is that area, while having a negative coefficient in all models, is found to be statistically significant in the unweighted models, but insignificant in the weighted models. However, the implication is the same, namely that mangroves exhibit decreasing returns to scale. The double-log formulation, however, results in the diminishing effect of area on wetland value as area increases so that the scale effect is minor for large wetland areas [27]. A similar relationship was found by Ghermandi et al. [29]. Brander et al. [17] and Woodward and Wui [27] find a statistically significant negative relationship as well and their estimates, -0.11 and $-0.168(-0.286)$, respectively, are similar to ours.

Finally, even though the weighted regressions have fewer explanatory variables and observations, their adjusted $R$ squared values are significantly higher than the unweighted models, indicating a better fit. When comparing the in-sample and out-of sample forecasts, we find that, on average, the unweighted models have a slightly lower forecast error, especially with regards to the out-of-sample MAPE. However, this difference is not large and we conclude that the weighted regressions do reasonably well in providing a benefits transfer function.

\section{Conclusions}

In this paper, we have provide an overview of the mangrove evaluation literature through a meta-regression analysis, the first in the wetlands literature that focuses specifically on mangrove forests. Like wetland studies, the literature on mangrove economic valuation is diverse in terms of types of ecosystem services, valuation methods, and location and consequently has produced a wide range of values. To assess how study characteristics and mangrove site characteristics have influenced economic valuations, we regressed annual per hectare values on different explanatory variables that encompass characteristics of the studies and the study sites, as well as GDP per capita. Since the data had several outliers, we also ran a robust regression to account for extreme values and weigh them accordingly. In addition, we ran a weighted robust regression (weighing studies equally rather than obesrvations) to allow for possible correlation across observations. Finally, we investigated the cross effects between service type and GDP per capita since each service may be valued differently based on the socio-economic conditions of the hosting country. 
According to the weighted robust regressions, we find that employing the CVM and RC methods results in higher values than other methods of valuation, with the CVM being the highest. Other factors that have a positive effect are protection of the site and GDP per capita, the latter being a common finding among previous wetland meta-analyses. In the model without the interaction effects, indirect use and nonuse values are higher than direct use values, with nonuse values the highest. In this model, we also find that having a foreign exchange component in the value results in higher valuations. Including cross effects results in values in the Middle East and Africa being higher than elsewhere, while coastal protection and carbon sequestration have the lowest values and nonuse values the highest. Also, the coefficients of the interaction terms show that coastal protection and carbon sequestration are more highly valued, and nonuse values and forestry are less valued in countries with higher per capita GDP. The unexpected result of the negative sign of the nonuse cross term is attributed to the high estimates reported for Egypt, which has a lower than the average GDP per capita of countries in our dataset. A final result is that mangroves exhibit decreasing returns to scale as evidenced by the fact that marginal value was found to be lower than average value.

We estimated transfer errors of the models to gauge their performance for the purpose of a benefits transfer. The result was that there were slight differences between the models since all transfer errors are between $35 \%$ and $54 \%$, a range that is within the lower end of previous estimates in the literature.

A recommendation is that primary studies provide more comprehensive information pertaining to several aspects. The first is the state of the environmental health of mangrove forests. While some studies do make this information known, this is not always the case and like any natural resource, the ecological functioning and economic values of mangrove forests are largely dependent on their environmental health and soundness. The second is the type of management of the resource such as fisheries and forestry, which is not always clarified in the original studies. The yields of fisheries and forests are affected by the form of management [51,64], thereby necessitating the inclusion of pertinent management information in any evaluation study. Finally, we recommend that if papers evaluate physically quantifiable goods, like fish or timber, they include the physical quantities of these goods. This facilitates comparing the productivity of mangrove forests across countries and independently of the method of valuation.

\section{Acknowledgments}

Funding for this project was provided by the USDA Forest Service Southern Research Station, through a joint venture agreement \#10-JV-11330143-129 is gratefully acknowledged. The views reflected herein are those of the authors and do not necessarily reflect the agency's views. Partial funding for Salem by the Faculty of Economics and Political Science, Cairo University through the Massiha/ Elmokadem Scholarship is also gratefully acknowledged.

\section{Conflict of Interest}

The authors declare no conflict of interest. 


\section{References and Notes}

1. Warne, K. Forests of the tides. National Geographic Magazine, February 2007. Available online: http://ngm.nationalgeographic.com/2007/02/mangroves/warne-text (accessed on 27 December 2011).

2. Stedman, S.; Dahl, T.E. Status and Trends of Wetlands in the Coastal Watersheds of the Eastern United States 1998 to 2004; National Oceanic and Atmospheric Administration, National Marine Fisheries Service and U.S. Department of the Interior, Fish and Wildlife Service: Charleston, SC, USA, 2008; p. 32.

3. Sathirathai, S. Economic Valuation of Mangroves and the Roles of Local Communities in the Conservation of Natural Resources: Case Study of Surat Thani, South of Thailand; Research Report no. rr1998061; Economy and Environment Program for Southeast Asia (EEPSEA): Bangkok, Thailand, 1997.

4. Mitsch, W.J., Gosselink, J.G. Wetlands; John Wiley \& Sons, Inc.: New York, NY, USA, 2000.

5. For a review of mangroves, see William J. Mitsch and James G. Gosselink. Wetlands; John Wiley \& Sons, Inc.: New York, NY, USA, 2000.

6. Dahdouh-Guebas, F.; Jayatissa, L.P.; di Nitto, D.; Bosire, J.O.; Lo Seen, D.; Koedam, N. How effective were mangroves as a defence against the recent tsunami. Curr. Biol. 2005, 15, 443-447.

7. Barbier, E. Valuing ecosystem services as productive inputs. Econ. Policy 2007, 22, 177-230.

8. Blaber, S.J. Mangroves and fishes: Issues of diversity, dependence, and dogma. Bull. Mar. Sci. 2007, 80, 457-472.

9. Bann, C. An Economic Analysis of Alternative Mangrove Management Strategies in Koh Kong Province, Cambodia; EEPSEA Research Report, p. 58; Environment and Economics Program for South East Asia, International Development Research Centre: Ottawa, Canada, 1997.

10. Chong, J. Protective Values of Mangrove and Coral Ecosystems: A Review of Methods and Evidence; IUCN: Gland, Switzerland, 2005.

11. Badola, R.; Hussain, S.A. Valuing ecosystem functions: An empirical study on the storm protection function of Bhitarkanika mangrove ecosystem, India. Environ. Conserv. 2005, 32, $85-92$.

12. Spalding, M. The global distribution and status of mangrove ecosystems. Int. Newsl. Coast. Manag. Intercoast Netw. 1997, 1, 20-21.

13. Untawale, A.G. Asia Country Reports: India. In Mangroves of Asia and the Pacific: Status and Management; Technical Report, UNDP/UNESCO Research and Training Pilot Programme on Mangrove Ecosystems in Asia and the Pacific; Natural Resources Management Center and National Mangrove Committee, Ministry of Natural Resources: Quezon City, Philippines, 1986; pp. 51-87.

14. Ruitenbeek, J. Mangrove Management: An Economic Analysis of Management Options with a Focus on Bintuni Bay, Irian Jaya; Environmental Management Development in Indonesia Project (EMDI) Environmental Reports; School for Resource and Environmental Studies, Dalhousie University, Halifax, Nova Scotia, Canada and the Ministry of State for Population and Environment, Jakarta, Indonesia ; Dalhousie University Printing Centre: Halifax, Nova Scotia, Canada, 1992; Volume 8, p. 51. 
15. Hirway, I.; Goswami, S. Valuation of Coastal Resources: The Case of Mangroves in Gujarat; Academic Foundation/ Centre for Development Alternatives: Ahmedabad, India, 2007; p. 49.

16. Ronnback, P. The ecological basis for economic value of seafood production supported by mangrove ecosystems. Ecol. Econ. 1999, 29, 235-252.

17. Brander, L.; Florax, R.; Vermaat, J. The empirics of wetland valuation: A comprehensive summary and a meta-analysis of the literature. Environ. Resour. Econ. 2006, 33, 223-250.

18. Mangroves are highly susceptible to oil exposure due to the fact that they, where present, are a boundary between land and sea and are hence prime locations for oil accumulation after spills. Past oil spills have resulted in both lethal and sub-lethal effects to mangrove forests. Furthermore, once a spill has occurred, the forests are difficult to protect and clean up due to the convoluted nature of the trees and the fact that the forests are relatively hard to access by humans (Hoff, R. Oil Spills in Mangroves: Planning \& Response Considerations; National Oceanic and Atmospheric Administration, NOAA Ocean Service, Office of Response and Restoration: Seattle, WA, USA, 2002. Available Online: http://response.restoration.noaa.gov/book_shelf/34_ mangrove_complete.pdf (accessed on 12/5/2010). Added to this are the burrowing activities of crustaceans, which are typically found in mangrove forests. Increasingly high quantities of oil are entering the marine environment through three main routes: Natural seeps, offshore drilling and production and transportation losses. Together, these factors lead to persistent and high levels of oil pollution both on the surface and deep within the soil (Lewis, R. Impact of oil spills on mangrove forests. In Biology and Ecology of Mangroves, Tasks for Vegetation Science; Teas, H.J., Junk, W., Eds.; Springer: Hague, the Netherlands, 1983).

19. National Oceanic and Atmospheric Administration (NOAA). Available online: http://response. restoration.noaa.gov/topic_subtopic_entry (accessed on 12 March 2011).

20. Bennett, E.; Reynolds, C. The value of a mangrove area in sarawak. Biodivers. Conserv. 1993, 2 , 359-375.

21. Costanza, R.; d'Arge, R.; de Groot, R.; Farber, S.; Grasso, M.; Hannon, B.; Limburg, K.; Naeem, S.; O’Neill, R.; Paruelo, J.; et al. The value of the world's ecosystem services and natural capital. Nature 1997, 387, 253-261.

22. Barbier, E.; Strand, I. Valuing mangrove-fishery linkages. Environ. Resour. Econ. 1998, 12, 151-166.

23. Bann, C. A Contingent Valuation of the Mangroves of Benut, Johor State, Malaysia; Preparation of an Integrated Management Plan for the Sustainable Use of the Johor Mangrove Forest; Johor State Forestry Dapartment/ DANCED/ Darudec: Johor, Malaysia, 1999; p. 79.

24. Cooper, E.; Burke, L.; Bood, N. Coastal Capital: Belize the Economic Contribution of Belize's Coral Reefs and Mangroves; World Resources Institute: Washington, DC, USA, 2009; p. 54.

25. Brower, R.; Langford, I.; Bateman, I.; Crowards, T.; Turner, R. A Meta-Analysis of Wetland Contingent Valuation Studies; CSERGE Working Paper GEC 97-20; the Centre for Social and Economic Research on the Global Environment (CSERGE): Norwich, UK, 1997.

26. Heimlich, R.; Wiebe, K.; Claassen, R.; Gadsby, D.; House, R. Wetlands and agriculture: Private interests and public benefits. In Agricultural Economic Report; Resource Economic Division, Economic Research Service, USDA: Washington, DC, USA, 1998; p. 94. 
27. Woodward, R.; Wui, Y. The economic value of wetland services: A meta-analysis. Ecol. Econ. 2001, 257-270.

28. Chen, D.-R. Essays on Improving the Econometric Estimation of Wetlands Values via Meta-Analysis. Master Thesis, Agricultural, Environmental, and Development Economics, Ohio State University: Columbus, OH, USA, 2010.

29. Ghermandi, A.; van den Bergh, J.C.J.M.; Brander, L.; de Groot, H.; Nunes, P.A.L.D. The Values of Natural and Constructed Wetlands: A Meta-Analysis; Tinbergen Institute: Amsterdam, Holland, 2009; Tinbergen Institute Discussion Paper, p. 22.

30. Hamilton, L.S.; Snedaker, R.E. Handbook for Mangrove Area Management; UNEP and East West Center, Environment and Policy Institute: Honolulu, HI, USA, 1984; p. 126.

31. Martosubroto, P.; Naamin, N. Relationship between tidal forests (mangroves) and commercial shrimp production in Indonesia. Mar. Res. Indones. 1977, 18, 81-86.

32. Turner, R.E. Intertidal vegetation and commercial yields of penaeid shrimp. Trans. Am. Fish. Soc. 1977, 106, 411-416.

33. Pauly, D.; Ingles, J. The relationship between shrimp yields and intertidal vegetation (mangrove) areas: A reassessment. In Ecosistemas de Manglar en América Tropical. Instituto de Ecología A.C. México; Yáñez-Arancibia, A., Lara-Domínguez, A.L., Eds.; UICN/ORMA, Costa Rica, NOAA/NMFS: Silver Spring, MD, USA, 1999; pp. 311-318.

34. National Research Council of the National Academies. Valuing Ecosystem Services: Toward Better Environmental Decision-Making; Committee on Assessing and Valuing the Services of Aquatic and Related Terrestrial Ecosystems, Water Science and Technology Board, Division on Earth and Life Studies, The National Academies Press: Washington, DC, USA, 2005.

35. Barbier, E.B. Valuing the environment as input: Review of applications to mangrove-fishery linkages. Ecol. Econ. 2000, 35, 47-61.

36. Freeman, A.M. The Measurement of Environmental \& Resource Values: Theory and Methods, 2nd ed.; Resources for the Future Press: Washington, DC, USA, 2003.

37. Barbier, E.B. An approach to economic evaluation of tropical wetlands: With examples from Guatemala and Nicaragua. In Caribbean Ecology and Economics; Girvan, N.P., Simons, D., Eds.; Caribbean Conservation Association: St. Michael, Barbados, 1991; pp. 207-231.

38. Barbier, E.B.; Acreman, M.; Knowler, D. Economic Valuation of Wetlands: A Guide for Policy Makers and Planners; Ramsar Convention Bureau: Gland, Switzerland, 1997.

39. Brouwer, R. Environmental value transfer: State of the art and future prospects. Ecol. Econ. 2000, 32, 137-152.

40. Carson, R.T.; Hanemann, W.M. Contingent Valuation. In the Handbook of Environmental Economics: Valuing Environmental Changes; Maler, K.-G., Vincent, J.R., Eds.; Elsevier: Amsterdam, the Netherlands, 2005; Volume 2.

41. For more details about conducting a proper CV study, see Carson, R.T.; Hanemann, W.M. Contingent Valuation. In the Handbook of Environmental Economics: Valuing Environmental Changes; Maler, K.-G., Vincent, J.R., Eds.; Elsevier: Amsterdam, the Netherlands, 2005; Volume 2.or Boyle, K. Contingent valuation in practice. In A Primer on Nonmarket Valuation; Champ, P., Boyle, K., Brown, T., Eds.; Kluwer Academic Publishers: Dordrecht, the Netherlands, 2003. 
42. Parsons, G.R. The travel cost model. In A Primer on Nonmarket Valuation; Champ, P., Boyle, K., Brown, T., Eds.; Kluwer Academic Publishers: Dordrecht, The Netherlands, 2003.

43. Phaneuf, D.J.; Smith, V.K. Recreation demand models. In the Handbook of Environmental Economics: Valuing Environmental Changes, Maler, K.-G., Vincent, J.R., Eds., Elsevier: Amsterdam, the Netherlands, 2005; Volume 2.

44. The proper definition involves the use of the compensated demand curve, but it may not be observable, so the ordinary demand curve is used (Brouwer, R. Environmental value transfer: State of the art and future prospects. Ecol. Econ. 2000, 32, 137-152).

45. Stanley, T.D.; Jarrell, S.B. Meta-regression analysis: A quantitative method of literature surveys. J. Econ. Surv. 1989, 3, 161-170.

46. Stanley, T.D. Wheat from chaff: Meta-analysis as quantitative literature review. J. Econ. Perspect. 2001, 15, 131-150.

47. Mangroves generally occur in the region confined by $30^{\circ}$ north and south of the equator. The exceptions to this are a few areas in the North (Japan and Bermuda) and South (New Zealand, Australia and the east coast of South Africa) (Spalding, M. The global distribution and status of mangrove ecosystems. Int. Newsl. Coast. Manag. Intercoast Netw. 1997, 1, 20-21). However, none of these countries are included in our valuations.

48. Bennett, E.M.; Peterson, G.D.; Gordon, L.J. Understanding relationships among multiple ecosystem services. Ecol. Lett. 2009, 12, 1394-1404.

49. Barbier, E.B. Progress and challenges in valuing coastal and marine ecosystem services. Rev. Environ. Econ. Policy. 2012, 6, 1-19.

50. Guerrya, A.D.; Ruckelshausa, M.H.; Arkemaa, K.K.; Bernhardta, J.R.; Guannela, G.; Kima, C.-K.; Marsikb, M.; Papenfusa, M.; Tofta, J.E.; Verutesa, G.; et al. Modeling benefits from nature: Using ecosystem services to inform coastal and marine spatial planning. Int. J. Biodivers. Sci. Ecosyst. Serv. Manag. 2012, iFirst, 1-15.

51. Ong, P.; Padilla, J. Assessment of fisheries-related functions of the Pagbilao experimental mangrove forest. In Mangroves or Fishponds? Valuation and Evaluation of Alternative uses of a Mangrove Forest in the Philippines; Janssen, R., Padilla, J.E., Eds.; Institute for Environmental Studies (IVM), Vrije Universiteit: Amsterdam, the Netherlands, 1996.

52. Gammage, S. Estimating the Returns to Mangrove Conversion: Sustainable Management or Short Term Gain? Environmental Economics Programme, Discussion Paper; International Institute for Environment and Development: London, UK, 1997; p. 48 cited in Spaninks, F.; Beukering, P. Economic Valuation of Mangrove Ecosystems: Potential and Limitations; CREED Working Paper Series; International Institute for Environment and Development, Vrije Universiteit: Amsterdam, The Netherlands, 1997; Working paper No. 14, p. 53.

53. Sanchirico, J.N.; Mumby, P. Mapping ecosystem functions to the valuation of ecosystem services: Implications of species-habitat associations for coastal land-use decisions. Theor. Ecol. 2009, 2, 67-77.

54. Sanchirico, J.N.; Springborn, M. How to get there from here: Ecological and economic dynamics of ecosystem service provision. Environ. Resource Econ. 2011, 48, 243-267. 
55. OLS estimates in meta-analyses should only be used for hypothesis-testing if robust standard errors are used (Nelson, J.P.; Kennedy, P.E. The use (and abuse) of meta-analysis in environmental and natural resource economics: An assessment. Pennsylvania State University, unpublished paper, 2008. Available online: http://ssrn.com/abstract $=1117490$ (accessed on 12 November 2011)). Nevertheless, we ran the OLS regression with standard errors, but got results that were very similar to those with robust standard errors.

56. We also ran the regression while manually excluding outliers that lie outside of logical cutoff points revealed by the data. Hence, we excluded observations representing the 3 lowest values and 4 highest values of annual per hectare values. The results were very similar to the those obtained by the robust regression, with the only difference being that in the former the estimated coefficient of per capita GDP was significant. Consequently, we have not reported the results of the OLS regression.

57. The robust regression process is one whereby a regression is first run and the observations with a Cook's D (Cook, R.D. Detection of influential observation in linear regression. Technometrics 1977, 19, 15-18) greater than 1 are excluded to eliminate gross outliers. An iterative process then proceeds where case weights from absolute residuals are generated in each step and used for the regression in the following step. The process continues until the maximum change in weights falls below a pre-determined tolerance threshold.

58. Mrozek, J.R.; Taylor, L.O. What determines the value of life? A meta-analysis. J. Policy Anal. Manag. 2002, 21, 253-270.

59. Nelson, J.P.; Kennedy, P.E. The use (and abuse) of meta-analysis in environmental and natural resource economics: An assessment. Pennsylvania State University, unpublished paper, 2008. Available online: http://ssrn.com/abstract=1117490 (accessed on 12 November 2011).

60. We also ran the regression while clustering the observations of each to study to allow correlations between them while maintaining independence across studies. The results were very similar to those reported for OLS with robust standard errors, with the only exception that the estimated coefficient for area became insignificant. Consequently, we have not reported the results of the cluster regression.

61. Another consideration taken into account when choosing the studies to be included is that the valuations be measured in the absence of mangrove conversion into other uses. For example, aquaculture is only considered if the existing mangrove swamps are used for this activity, but not if the mangroves are cleared for the purposes of aquaculture.

62. Costanza, R.; Farber, S.; Maxwell, J. Valuation and management of wetland ecosystems. Ecol. Econ. 1989, 1, 335-361. 
63. The first approach was used by Barbier, E.; Strand, I. Valuing mangrove-fishery linkages. Environ. Resour. Econ. 1998, 12, 151-166., the second and third were used by Gammage, S. Estimating the Returns to Mangrove Conversion: Sustainable Management or Short Term Gain? Environmental Economics Programme, Discussion Paper; International Institute for Environment and Development: London, UK, 1997; p. 48 (Spaninks, F.; Beukering, P. Economic Valuation of Mangrove Ecosystems: Potential and Limitations; CREED Working Paper Series; International Institute for Environment and Development, Vrije Universiteit: Amsterdam, The Netherlands, 1997; Working paper No. 14, p. 53) and the fourth was used by Aburto-Oropeza, O.; Ezcurra, E.; Danemann, G.; Valdez, V.; Murray, J.; Sala, E. Mangroves in the Gulf of California increase fishery yields. Proc. Natl. Acad. Sci. USA 2008, 105, 10456-10459.

64. Engle, V. Estimating the provision of ecosystem services by gulf of mexico coastal wetlands. Wetlands. 2011, 31, 179-193.

65. This fact also holds for the original number of observations before exclusion of studies.

66. Note that the their study includes all types of wetlands and not just mangroves (Brander, L.; Florax, R.; Vermaat, J. The empirics of wetland valuation: A comprehensive summary and a meta-analysis of the literature. Environ. Resour. Econ. 2006, 33, 223-250).

67. Halvorsen, R.; Palmquist, R. The interpretation of dummy variables in semilogarithmic equations. Am. Econ. Rev. 1980, 70, 474-475.

68. The relationship between the coefficient and the relative effect of the categorical variable on the dependent variable is given by $c=\ln (1+g)$ where $\mathrm{c}$ is the estimated coefficient and $g=\left(Y_{1}-Y_{0}\right) / Y_{0}$ where $Y_{1}$ and $Y_{0}$ denote the value of the dependent variable when the categorical variable takes the value of 1 and 0 , respectively (Halvorsen, R.; Palmquist, R. The interpretation of dummy variables in semilogarithmic equations. Am. Econ. Rev. 1980, 70, 474-475).

69. Barbier, E.; Strand, I.; Sathirathai, S. Do open access conditions affect the valuation of an externality? Estimating the welfare effects of mangrove-fishery linkages in Thailand. Environ. Resour. Econ. 2002, 21, 343-367.

(C) 2012 by the authors; licensee MDPI, Basel, Switzerland. This article is an open access article distributed under the terms and conditions of the Creative Commons Attribution license (http://creativecommons.org/licenses/by/3.0/). 